\title{
Gravity and density variations of the tilted Tottabetsu plutonic complex, Hokkaido, northern Japan: implications for subsurface intrusive structure and pluton development
}

\author{
Hiroyuki Kamiyama ${ }^{1}$, Akihiko Yamamoto ${ }^{2}$, Takeshi Hasegawa ${ }^{3}$, Takanori Kajiwara ${ }^{1}$, and Toru Mogi ${ }^{1}$ \\ ${ }^{1}$ Institute of Seismology and Volcanology, Graduate School of Science, Hokkaido University, Sapporo, Japan \\ ${ }^{2}$ Department of Earth Sciences, Faculty of Science, Ehime University, Matsuyama, Japan \\ ${ }^{3}$ Department of Earth and Planetary Sciences, Graduate School of Science, Hokkaido University, Sapporo, Japan
}

(Received September 9, 2005; Revised November 9, 2005; Accepted November 10, 2005)

\begin{abstract}
An exposed cross section of the tilted Tottabetsu plutonic complex allows direct evaluation of its original 2-D cross-sectional shape and pretilting vertical density variations in both the pluton and the country rocks, which serves as a strong constraint in gravity modeling that complements information on the 'missing' pretilting horizontal dimension of this tilted pluton. The pluton is stratified with the uppermost thin granitic unit $(\sim 1$ $\mathrm{km}$ thick) and the underlying thick gabbro-diorite units ( $\sim 9-\mathrm{km}$ thick) that preserve a stratigraphic record of numerous hotter replenishments in the form of alternation of originally horizontal mafic sheets and cumulate layers. Both the pluton and the country rocks show systematic density increase with pretilting crustal depth, but density contrast of the pluton with the country rocks varies between each unit. The 2-D cross-sectional shape and gravity analysis revealed that the pluton had a vertically-elongated shape with vertical side walls before tilting. The vertical side walls, together with the stack of the originally horizontal sheets and cumulate layers, suggests that the pluton grew only vertically by piston mechanism. The very thick, exposed cross section provides unequivocal evidence for development of such a pluton with this unusual shape and mass distribution, which has been inferred elsewhere only by some geophysical studies.
\end{abstract}

Key words: tilted pluton, pluton emplacement, gravity anomaly, rock density.

\section{Introduction}

Construction of a pluton is a multi-process geological event including emplacement, growth and solidification of magma bodies within the Earth's crust. Important information on the mechanism by which plutons are constructed is preserved in their shapes and internal structures. However, exposures of the overwhelming majority of plutons only provide sections that can be approximated horizontally, so information on the vertical variations in shape, lithology and internal structures is severely limited.

Considerable interest has focused on geophysical data bearing on subsurface structures of plutons (Ameglio and Vigneresse, 1999). Especially, gravity techniques have widely been applied to studies of plutons (e.g. Ameglio and Vigneresse, 1999 and references therein). Although gravity (and other geophysical) data can place important constraints on overall subsurface geometry, their limited spatial resolution does not allow evaluation of outcrop-scale features of unexposed parts of plutons. Furthermore, lack of exact knowledge of vertical variation in density contrast between plutons and country rocks leads to unreliable gravity estimates of shape and depth extent of plutons (Pitcher, 1979). For many plutons and their country rocks, density variation should be much more pronounced in the vertical than in the

Copy right(c) The Society of Geomagnetism and Earth, Planetary and Space Sciences (SGEPSS); The Seismological Society of Japan; The Volcanological Society of Japan; The Geodetic Society of Japan; The Japanese Society for Planetary Sciences; TERRAPUB horizontal dimension, but vertical variation in rock density is seldom taken into account.

Another approach of geological study only can be possible in the field of rare vertical cross sections of plutons exposed in tilted crustal sections. This allows direct observation of cross-sectional shape and vertical variations in lithology and small-scale structures (e.g. Miller and Miller, 2002). Nevertheless, it is still largely limited to 2-D surface exposures. Geophysical study would complement information on the 'missing' original horizontal dimension of such tilted plutons. To our knowledge, however, none of the geophysical studies have been applied to the tilted plutons.

An exposed cross section of the tilted Miocene Tottabetsu plutonic complex (TPC) provides not only its 2-D crosssectional shape, but also a stratigraphic record of crystallization and recurrent replenishments. Furthermore, the cross-sectional exposure allows direct evaluation of pretilting vertical variation in density contrast between the pluton and the country rocks, which serves as a strong constraint in gravity analysis. Here we present field and gravity evidence that describes the geometry, mass distribution and internal structure of this tilted pluton, which suggest that the pluton grew only vertically by piston mechanism to form an unusually thick cylindrical pile of mafic rocks and an overlying thin granitic cap. 

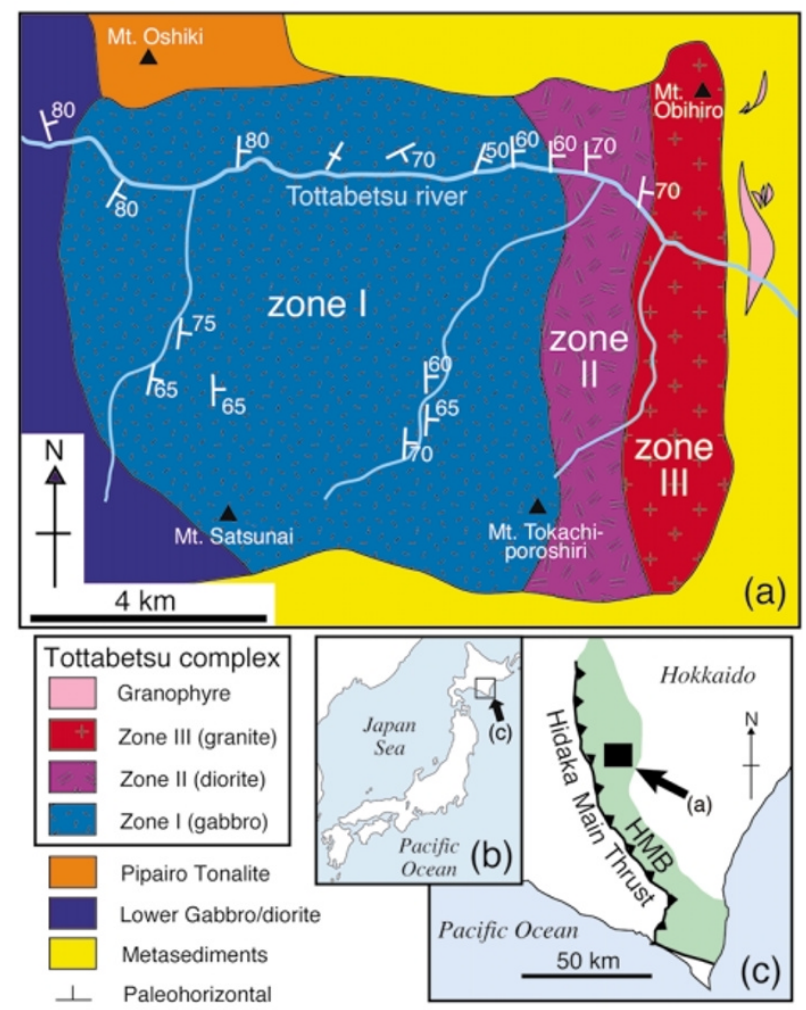

Fig. 1. Geologic map of the Tottabetsu plutonic complex modified from Suetake (1997) (a), and simplified maps of the Japanese Islands (b) and south-central Hokkaido (c). Paleohorizontals are inferred from mafic sheets, pipes and cumulate layering and foliations.

\section{Geologic Background}

The Hidaka metamorphic belt (HMB), north Japan (Fig. 1(b) and (c)), represents a tilted cross section through part of continental crust (Komatsu et al., 1983). It is exposed as a consequence of collision of Kuril fore arc and Northeast Japan arc due to southwestward migration of the former since the late Miocene (Kimura, 1996). Foliation and banding of the metamorphic rocks and layering of the plutonic rocks in this crustal section in general strike roughly N-S and dip steeply eastward. Metamorphic grade systematically increases westward from zeolite to granulite facies, indicating that the crustal depth increases westward. The maximum pressure and temperature conditions were 7 kbar and $830^{\circ} \mathrm{C}$ (Osanai et al., 1991). A major east-dipping thrust, the Hidaka main thrust (HMT), bounds the western edge of the HMB (Fig. 1(c)).

The TPC (Fig. 1(a)), which constitutes part of the HMB, intrudes metamorphosed equivalents of sedimentary rocks of the Nakanogawa group along its northeastern, eastern and southern margins, and is surrounded by a contact aureole that overprints greenschist- to amphibolite-facies assemblages (Takahashi, 1992). The TPC is bounded on the northwest by the Pipairo tonalite, and on the west by the Lower gabbro-diorite (LGD) that consists of gabbros and subordinate diorites. The regional subsolidus deformation in the Pipairo tonalite and the LGD implies that they predated the TPC, which is undeformed except for minor fracturing.

\section{Cross-Sectional View of the TPC}

The TPC is roughly rectangular in plan, measuring $8 \mathrm{~km}$ by $12 \mathrm{~km}$ (Fig. 1(a)). There is little topographic control on the map pattern of the complex, implying that the complex presently has steeply dipping sides. Paleohorizontals inferred from magmatic structures (see below) roughly strike $\mathrm{N}-\mathrm{S}$ and dip steeply eastward in the range between $50^{\circ}$ and $90^{\circ}$ (Fig. 1(a)). On the basis of the dips of the paleohorizontals and E-W extent of the complex, thickness of the entire complex is estimated to be $\sim 10 \mathrm{~km}$. Width of the complex is nearly constant, $\sim 8 \mathrm{~km}$ in exposed lateral $(\mathrm{N}-\mathrm{S})$ extent, throughout the entire stratigraphic succession. The paleohorizontals are roughly perpendicular to the exposed original side walls and subparallel to the original roof of the pluton. Thus, in terms of the 2-D cross-sectional exposure, the TPC apparently had a cylindrical form with vertical side walls and a flat roof before tilting.

Suetake (1997) divided the TPC, from west to east, into zones I to III on the basis of dominant lithology of each mappable area (Fig. 1(a)). Zone I ( 7-km thick) is predominantly composed of gabbroic rocks and occupies the lower two thirds of the complex. It is overlain by zone II (1-1.5-km thick), which consists of wide variety of dioritic rocks. Zone III (1-1.5-km thick) forms the granitic cap at the uppermost part of the complex.

In zone I, steeply east-dipping sheets of fine-grained gabbros are interlayered with and variably chilled against medium-grained gabbroic and leucodioritic cumulate layers. The alternation of sheets and cumulate layers are taken as evidence for ponding of recurrently injected mafic magmas on the progressively aggrading crystal-rich base of a more evolved, crystal-poor magma chamber (e.g. Wiebe and Collins, 1998). Lobate basal margins of the gabbroic sheets, flame structures, and pegmatitic pipes penetrating the gabbroic sheets serve as indicators of 'way-up' and horizontals at the time of their formation (Wiebe and Collins, 1998). The pipes have axes roughly perpendicular to the sheets and cumulate layers, indicating that the sheets and layers were originally horizontal. Similar east-dipping sheets and cumulate layers are also seen in zone II, but the rocks are distinctly more felsic, intermediate in composition. The overall compositional difference between zones I and II is essentially attributed to compositional difference of the injected magmas. By contrast, zone III consists of massive homogeneous granite that presumably formed as complementary fractionates to the cumulates in zones I and II.

\section{Density Variations}

Densities of surface rock samples were determined by laboratory measurements. Since the HMB represents the tilted cross section through lower to upper continental crust whose paleodepth increases westward (Komatsu et al., 1983), systematic E-W variations in rock densities might be expected. For this reason, results of the density measurements were plotted versus E-W distance from the HMT that defines the deepest part of the crustal section (Fig. 2).

Significantly, densities of the felsic country rocks including metasedimentary and tonalitic rocks systematically decrease eastward from $\sim 2.8$ to $\sim 2.6 \mathrm{~g} / \mathrm{cm}^{3}$ for over the dis- 


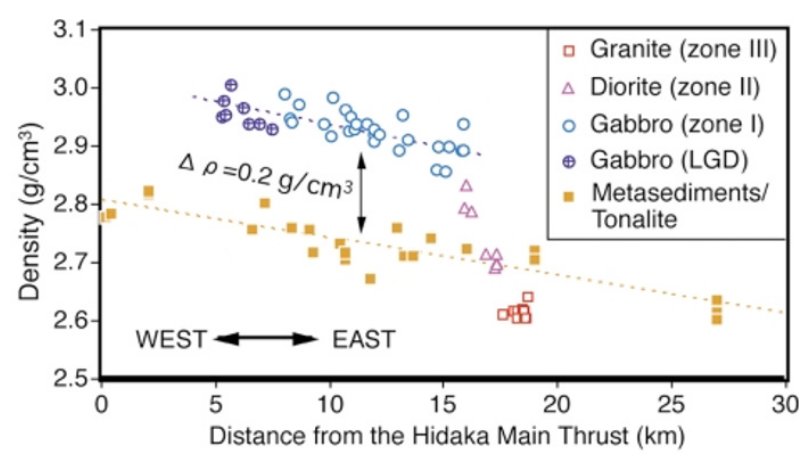

Fig. 2. Rock densities plotted versus E-W distance from the Hidaka Main Thrust.

tance of $\sim 30 \mathrm{~km}$. As there is little correlation between the measured densities and whole-rock chemical compositions, the eastward decrease in density of these felsic country rocks appears to reflect change in proportion of constituent minerals primarily due to the decreasing metamorphic grade. Similar systematic eastward decrease in rock density is also observed for the TPC and the LGD. Densities of the gabbros from zone I and the LGD gently decrease eastward with concomitant increase in modal hornblende at the expense of anhydrous mafic minerals. However, density contrast of these gabbros relative to the felsic country rocks at a given distance from the HMT is found to be nearly constant, $\sim 0.2 \mathrm{~g} / \mathrm{cm}^{3}$. The diorites in zone II show marked eastward decrease in their densities, reflecting eastward increase in $\mathrm{SiO}_{2}$ content. The average density contrast of the diorites relative to the metasedimentary country rocks of comparable distance from the HMT is close to $0.1 \mathrm{~g} / \mathrm{cm}^{3}$. Granites of zone III show negative density contrast with the metasedimentary country rocks. The average density contrast of the granite relative to the metasedimentary country rocks is close to $-0.1 \mathrm{~g} / \mathrm{cm}^{3}$.

\section{Gravity Anomaly and Subsurface Contact}

Previous gravimetric studies (e.g., Yamamoto et al., 2001) do not illustrate detailed features of the TPC due to lack of gravity data and nonuniformity of station coverage. We performed gravity measurements such that station coverage would be as uniform and dense as possible in the study area. Finally, 250 gravity data were newly obtained using the Scintrex gravimeter with a precision of \pm 0.05 $\mathrm{mGal}$. Elevations were determined using differential GPS, spot heights and contours on 1/25,000 topographic maps published by Geographical Survey Institute (Japan). In total, 887 gravity data were reduced for free-air and Bouguer corrections as well as for terrain effects, using a density of $2.67 \mathrm{~g} / \mathrm{cm}^{3}$. Terrain corrections were based on the method of Yamamoto (2002).

Despite the limited distribution of gravity stations, the Bouguer anomaly map does show some distinct correlations between the exposed area of the TPC and local gravity field impinged upon eastward declining regional gravity field (Fig. 3). As expected from the positive density contrasts of the gabbros and diorites relative to the felsic country rocks, an east-plunging ridge of gravity high is seen associated with the exposure of zones I and II. At the same time, a

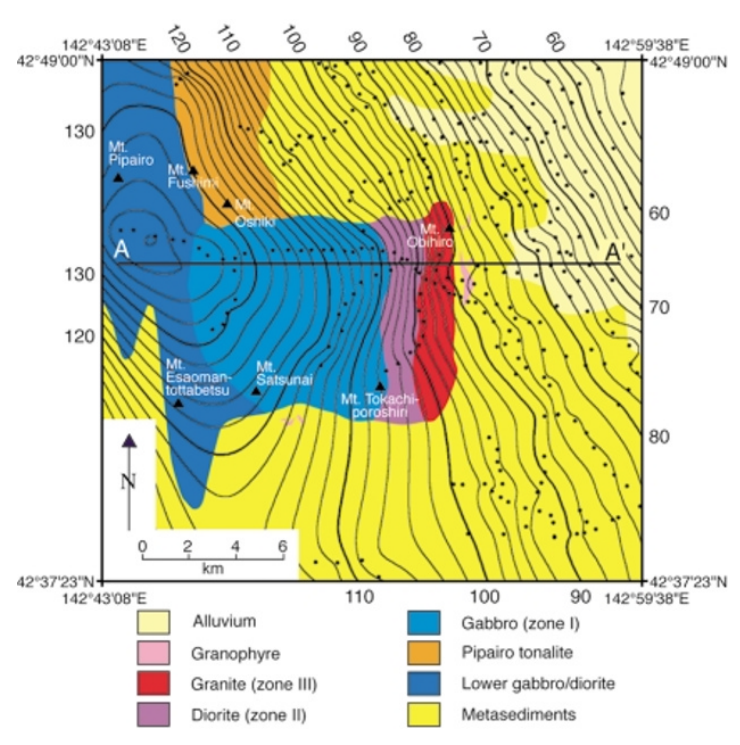

Fig. 3. Bouguer anomaly map of the Tottabetsu plutonic complex. Contours are in milligals. The black dots mark the locations of gravity stations. The profile line (A-A') shown in Fig. 4 is indicated.

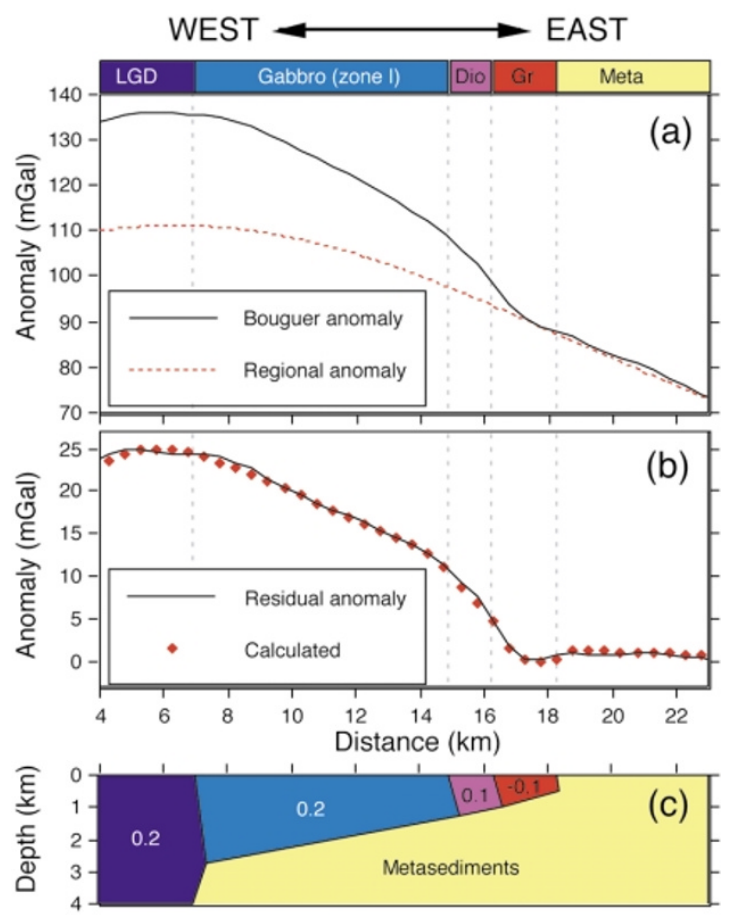

Fig. 4. Gravity interpretation along E-W profile A-A' (Fig. 3). (a) Bouguer gravity profile and subtracted regional gravity. (b) Residual anomaly and modeled gravity field. (c) 2-D model for the gravity profile. Density contrasts relative to the metasediments are shown in $\mathrm{g} / \mathrm{cm}^{3}$.

weak gravity low is seen associated with the exposure of zone III, concordant with the negative density contrasts of the granite relative to the metasedimentary rocks.

The Bouguer anomalies include the regional effects induced by far-located or deep-seated sources unrelated to the TPC. Specifically, in the HMB, it must also include the effect of the lateral variation in rock densities (Fig. 2). To remove these regional effects, long-wavelength anomaly calculated by running average of a square grid of 20 by 20 
$\mathrm{km}^{2}$ was subtracted from the Bouguer anomaly (Fig. 4(a)). The specific grid size of 20 by $20 \mathrm{~km}^{2}$ was chosen in order for the resultant residual gravity at the exposed area of the country rocks to be flat. Figure 4(b) shows the residual anomaly and the gravity field calculated from the 2D model shown in Fig. 4(c). The gravity feature of the model closely matches the observed residual anomaly. The model shows that the subsurface contact between the TPC and metasedimentary rocks linearly deepens westward with a dip of $10^{\circ}-20^{\circ}$. Such a gently west-dipping contact is roughly perpendicular to the steeply east-dipping paleohorizontals inferred from the surface geology (Fig. 1), strongly supporting that the hidden pretilting side wall of the TPC was also nearly vertical.

\section{Discussion and Conclusions}

Our field observations suggest that the TPC was formed by simultaneous crystallization and recurrent replenishments during the evolution of a single magma chamber. This in turn means that the active magma chamber at any one time was much thinner than the entire complex.

When the magma chamber was replenished by new magma, the magma chamber must have inflated in order to accommodate the newly injected magma, space for which might be created by displacing country rocks aside, upward, or downward. The construction by gradual vertical stacking of the horizontal sheets does not match lateral displacement of country rocks as the mechanism of space creation. The country rocks therefore must have been displaced either upward by roof lifting or downward by floor depression as envisaged for some tabular intrusions (e.g. Cruden, 1998). We suggest that the space for the successive batches of hotter magmas was made by vertical displacement of faultbounded blocks of roof or floor country rocks with little horizontal displacement. Evidence consistent with this piston mechanism includes the originally vertical side walls and flat roof and near-constant attitudes of the paleohorizontal structures that were formed during deposition on the chamber floor.

According to recent compilations (e.g. Petford et al., 2000), most plutons are tabular with vertical dimension much shorter than horizontal ones, though a few works on tilted plutons has documented more equant shapes (Haeussler and Paterson, 1993; Bachl et al., 2001). Furthermore, strong positive correlation between horizontal and vertical dimensions in the compilations implies that plutons grow by both lateral spreading and vertical inflation as a general rule. However, the shape and growth style of the TPC clearly do not match this empirical rule. The TPC is unusual in that it has a cylindrical shape with vertical dimension slightly greater than horizontal one and was shown to have grown only by vertical inflation.

The TPC represents, to our knowledge, the only documented cross-sectional exposure of such a pluton with an unusually thick, cylindrical mass of mafic rocks overlain by a thin granitic cap. Plutonic complexes with similar shape and mass distribution to the TPC have also been inferred elsewhere, but only by geophysical studies (Bott and Tuson, 1973; Bott and Tantrigoda, 1987; Bauer et al., 2003). The very thick, exposed cross section of the TPC provides unequivocal evidence for development of such a pluton with the unusual shape and mass distribution.

Acknowledgments. We thank Hitoshi Mori and Hiroaki Takahashi for assistance in GPS measurements, Takashi Nakajima for many discussions, and Tadashi Usuki for providing part of rock samples. We would also like to thank Calvin Miller for helpful comments on the earlier version of the manuscript, and Masao Komazawa and Roman Teisseyre for reviews and comments that helped us clarify the manuscript.

\section{References}

Ameglio, L. and J. L. Vigneresse, Geophysical imaging of the shape of granitic intrusions at depth: a review, Understanding Granites: Integrating New and Classical Techniques, edited by A. Castro, C. Fernandez and J. L. Vigneresse, Geol. Soc. Lond. Spec. Pub., 168, 39-54, 1999.

Bachl, C. A., C. F. Miller, J. S. Miller, and J. E. Faulds, Construction of a pluton: evidence from an exposed cross section of the Searchlight pluton, Eldorado Mountains, Nevada, Geol. Soc. Am. Bull., 113, $1213-$ 1228, 2001.

Bauer, K., R. B. Trumbull, and T. Vietor, Geophysical images and a crustal model of intrusive structures beneath the Messum ring complex, Namibia, Earth Planet. Sci. Lett., 216, 65-80, 2003.

Bott, M. H. P. and D. A. Tantrigoda, Interpretation of the gravity and magnetic anomalies over the Mull Tertiary intrusive complex, NW Scotland, J. Geol. Soc. Lond., 144, 17-28, 1987.

Bott, M. H. P. and J. Tuson, Deep structure beneath the Tertiary volcanic regions of Skye, Mull and Ardnamurchan, North-west Scotland, Nature (Physical Science), 242, 114-116, 1973.

Cruden, A. R., On the emplacement of tabular granites, J. Geol. Soc. Lond., 155, 852-862, 1998.

Haeussler, P. J. and S. R. Paterson, Post-emplacement tilting and burial of the Guadalupe Igneous Complex, Sierra Nevada, California, Geol. Soc. Am. Bull., 105, 1310-1320, 1993.

Kimura, G., Collision orogeny at arc-arc junctions in the Japanese Islands, Island Arc, 5, 262-275, 1996.

Komatsu, M., S. Miyashita, J. Maeda, Y. Osanai, and T. Toyoshima, Disclosing of a deepest section of continental-type crust upthrust as the final event of collision of arcs in Hokkaido, North Japan, Accretion Tectonics in the Circum-Pacific Regions, edited by M. Hashimoto and S. Uyeda, pp. 146-165, Terra Sci. Pub. Co., Tokyo, 1983.

Miller, C. F. and J. S. Miller, Contrasting stratified plutons exposed in tilt blocks, Eldorado Mountains, Colorado River Rift, NV, USA, Lithos, 61, 209-224, 2002.

Osanai, Y., M. Komatsu, and M. Owada, Metamorphism and granite genesis in the Hidaka Metamorphic Belt, Hokkaido, Japan, J. Metamor. Geol., 9, 111-124, 1991.

Petford, N., A. R. Cruden, K. J. W. McCaffrey, and J. L. Vigneresse, Granite magma formation, transport and emplacement in the Earth's crust, Nature, 408, 669-673, 2000.

Pitcher, W. S., The nature, ascent and emplacement of granitic magmas, $J$. Geol. Soc. Lond., 136, 627-662, 1979.

Suetake, S., Heterogeneous structures in a plutonic complex: inferences from the Tottabetsu plutonic complex, the Main zone of the Hidaka metamorphic belt, Hokkaido, Mem. Geol. Soc. Jpn., 47, 57-74, 1997 (in Japanese).

Takahashi, Y., Petrological study of tonalitic rocks in the upper reaches of Satsunai River, Main Zone of the Hidaka Metamorphic BeltCoexistent relation of S-type with I-type granite, J. Geol. Soc. Jpn., 98, 295-308, 1992 (in Japanese).

Wiebe, R. A. and W. J. Collins, Depositional features and stratigraphic sections in granitic plutons: implications for the emplacement and crystallization of granitic magma, J. Struct. Geol., 20, 1273-1289, 1998.

Yamamoto, A., Spherical terrain corrections for gravity anomaly using a digital elevation model gridded with nodes at every $50 \mathrm{~m}$, J. Fac. Sci. Hokkaido Univ., 11, 845-880, 2002.

Yamamoto, A., M. Saito, K. Yamada, and H. Ishikawa, Gravity anomaly and crustal structure around the southern part of the Hidaka Collision Zone in Hokkaido, Japan, Geophys. Bull. Hokkaido Univ., 64, 21-49, 2001 (in Japanese).

H. Kamiyama (e-mail: kami@eos.hokudai.ac.jp), A. Yamamoto, T. Hasegawa, T. Kajiwara, and T. Mogi 